\title{
Antioxidant Activity of Pomegranate Juice and Punicalagin
}

\author{
Akram Aloqbi1, Ulfat Omar2,3*, Marwa Yousr², Mary Grace4, Mary Ann Lila4, Nazlin Howell² \\ ${ }^{1}$ Biology Department, Faculty of Sciences and Arts-Alkamel, University of Jeddah, Jeddah, KSA \\ ${ }^{2}$ Division of Nutrition and Metabolism, Faculty of Health and Medical Sciences, University of Surrey, Guildford, \\ Surrey, UK \\ ${ }^{3}$ Present Address: Biochemistry Department, Faculty of Science, King Abdulaziz University, Jeddah, KSA \\ ${ }^{4}$ Plants for Human Health Institute, Kannapolis, NC, USA \\ Email: "uomer@kau.edu.sa
}

Received 11 February 2016; accepted 14 June 2016; published 17 June 2016

Copyright (C) 2016 by authors and Scientific Research Publishing Inc.

This work is licensed under the Creative Commons Attribution International License (CC BY). http://creativecommons.org/licenses/by/4.0/

(c) (i) Open Access

\section{Abstract}

Plant polyphenols are reported to have bioactive properties, which may be used for protection against diseases. Therefore, the aim of this research was to investigate the antioxidant activities of a pomegranate tannin polyphenol compound, punicalagin and pomegranate juice. The presence of punicalagin in pomegranate husk (US) and pomegranate juice (US \& UK) was compared with a punicalagin standard using high performance liquid chromatography (HPLC) and liquid chromatography-mass spectroscopy (LC-MS) which are highly sensitive and selective analytical methods for the separation and identification of phenolic compounds and anthocyanins. Antioxidant mechanisms involving DPPH radical scavenging activity, hydrogen peroxide scavenging, ferrous chelating and reducing ability were also studied on pomegranate juice and standard punicalagin. The present study shows a high degree of similarity of HPLC and LC-MS results between the punicalagin commercial standard (Sigma Aldrich) and US pomegranate husk extracted with methanol. In contrast, in the methanol juice extract obtained from US and UK, higher hydrogen peroxide scavenging activity was achieved by $0.1 \mathrm{mg} / \mathrm{ml}$ from both punicalagin and pomegranate juice when compared with butylated hydroxytoluene (BHT) or trolox $(p \leq 0.01)$. Punicalagin and pomegranate juice exhibited ferrous chelating ability significantly lower than Ethylenediaminetetraacetic acid. These findings confirmed that punicalagin was present in pomegranate husk compared to pomegranate juice, as measured using a punicalagin standard. The antioxidant mechanism experiments concluded that, the pomegranate juice has a significantly higher radical scavenging activity in comparison with punicalagin $(p \leq 0.01)$. However, punicalagin showed significant ferrous chelating activity and reducing power ability in a dose-dependent manner as compared with pomegranate juice.

\footnotetext{
${ }^{*}$ Corresponding author.
} 
Keywords

HPLC, LC-MS, Punicalagin, Radical Scavenger, Ferrous Ion Chelating

\section{Introduction}

Antioxidants are essential components of the human diet and recently there has been a great interest in using rich sources of natural antioxidants such as plants and food additives as they consist of vitamins (vitamin E, C and $\beta$-carotene) and plant polyphenols. Natural antioxidants found that innutraceuticals and functional food plants are more advantageous than synthetic antioxidants like butylated hydroxytoluene (BHT) because of their ability to protect food against free radicals and reactive oxygen species (ROS) damage and reduce risk of chronic disease [1].

It is well known that human health condition is partly controlled through the dietary intake of plant polyphenols. Antioxidants prevent food degradation and thus are used as food additives [2]. It is, therefore, vital to improve our knowledge of polyphenol availability from diet.

Pomegranate fruit contains many phenolic compounds including flavonoids-anthocyanins, and other complex flavanoids and hydrolyzable tannins (punicalagin, gallic and ellagic acid), which are compounds with high antioxidant activity that may offer beneficial health properties. Around $92 \%$ of pomegranate antioxidant activity comes from hydrolysable tannins [3]. Punicalagin, ellagic acid and gallic acid are the polyphenols found in pomegranate [4]. The main component of pomegranate husk is punicalagin [5]-[7]. Punicalagin is reported to have anti-inflammatory, anti-cancer and anti-atherosclerotic properties [7]-[9]. Pomegranate polyphenols are thus considered as agents capable of restraining the effect of ROS on the body [8] [9].

Radicals are molecules with unpaired electrons that are highly reactive, e.g. hydroxyl radical $\mathrm{OH}^{*}$ and superoxide radical $\mathrm{O}_{2}^{--}$. Radicals form in all living organisms in normal metabolic pathways during oxidation reactions. The free radical concentration level increases under certain circumstances e.g. environmental stress, wounding and pathogen attack, and can damage the living organisms when left unchecked. Where cell membranes consist of unsaturated lipids [10], free radicals are reactive molecules that have the ability to react and damage all types of bio-molecules-lipid, proteins, carbohydrates and DNA. This damaging effect could lead to several diseases e.g. coronary heart disease, inflammation and cancer [11]. Pomegranate juice was, nevertheless, found to exert potent antioxidant activity against lipid peroxidation [12]. Consequently, the objective of this research was to investigate the antioxidant activities of a pomegranate tannin polyphenol compound, punicalagin and pomegranate juice.

\section{Materials and Methods}

\subsection{Materials}

Trolox, 2,2-Dipheny l-1-picrylhydrazyl (DPPH), $\mathrm{FeCl}_{2} \cdot 4 \mathrm{H}_{2}$, Ethylenediaminetetraacetic acid (EDTA), Butylated hydroxytoluene (BHT), ferrozine ascorbate, $\mathrm{H}_{2} \mathrm{O}_{2}$, potassium ferricyanide, phosphate buffer, ferric chloride, gallic acid, catechin, Folin-Ciocalteu reagent, sodium nitrite, aluminum chloride, glacial acetic acid, acetonitrile, and formic acid were obtained from Sigma-Aldrich Chemical Co, (Pool, UK). Ethanol, methanol, trichloroacetic acid (TCA), sodium carbonate and sodium hydroxide were purchased from Fisher Scientific (Loughborough, UK). PhenomenexSynergi $4 \mu \mathrm{m}$ Hydro-RP 80A column $(250 \mathrm{~mm} \times 4.6 \mathrm{~mm} \times 5 \mu \mathrm{m})$ and Phenomenex C18 5 $\mu \mathrm{m}$ column $(250 \mathrm{~mm} \times 3.0 \mathrm{~mm})$ were obtained from Torrance, CA, USA.

\subsection{Methods}

\subsubsection{Sample Preparation}

Fresh Spain pomegranates were purchased from the local store in UKand peeled, and the edible portions (seeds and arils) were juiced then stored at $-80^{\circ} \mathrm{C}$ overnight. The resulting pomegranate juice (PJ) was then freezedried for 7 days. The freeze-dried pomegranate (powder) was stored at $-80^{\circ} \mathrm{C}$ until analysed.

\subsubsection{Determination of Total Phenolic and Total Flavonoid Content}

The total phenolic content of pomegranate juice was determined using the Folin-Ciocalteu method described by 
Kim et al. (2002). A sample of $1 \mathrm{ml}$ pomegranate juice $(40 \mathrm{mg} / \mathrm{ml})$ was mixed with $10 \mathrm{ml}$ of deionised water and $1 \mathrm{ml}$ Folin-Ciocalteu reagent. After 5 minutes, $2 \mathrm{ml}$ of $2 \%$ sodium carbonate $(\mathrm{w} / \mathrm{v})$ was added to the solution. The mixture was incubated in a dark place at room temperature for 1 hour, whereby the absorbance of the solution was measured at $750 \mathrm{~nm}$ [13]. The standard curve was determined with gallic acid. The results were expressed as gallic acid equivalents. Zhishen et al. (1999) used an aluminum chloride colorimetric assay to determine the total flavonoid. A sample $(250 \mu \mathrm{l})$ from $(60 \mathrm{mg} / \mathrm{ml}$ pomegranate juice) or from different concentrations of catechin was added to $1.25 \mathrm{ml}$ deionised water and $75 \mu \mathrm{l}$ of $5 \% \mathrm{NaNO}_{2}$ (w/v). After 5 minutes, $150 \mu \mathrm{l}$ of $10 \%$ $\mathrm{AlCl}_{3}$ was added to the mixture and $0.5 \mathrm{ml}$ of $1 \mathrm{M} \mathrm{NaOH}(\mathrm{w} / \mathrm{v})$ and $275 \mu \mathrm{l}$ deinoised water were added to make up the total volume of the solution to $2.5 \mathrm{ml}$ and measure the absorbance at $510 \mathrm{~nm}$ [14]. The total flavonoid content of pomegranate juice was expressed in terms of catechin equivalents.

\subsubsection{Extraction of Sample for HPLC and LC-MS}

HPLC and LC-MS were carried out in North Carolina State University, United State. Freeze dried pomegranate samples (1 g) were extracted with $25 \mathrm{ml} 50 \%$ methanol in water, vigorously vortexed at room temperature for 30 minutes. Extracted samples were centrifuged at $1500 \times g$ for 3 minutesfor 10 minutes at $10^{\circ} \mathrm{C}$ using a Beckman GRP centrifuge. The supernatants were filtered through a Whatman No.1 filter paper in to a $50 \mathrm{ml}$ volumetric flask. The precipitate was re-extracted with another $25 \mathrm{ml}$ of 50\% methanol then centrifuged, and the supernatant was added to the previously collected solution. In order to make up the volume of the volumetric flask, $50 \%$ methanol was used. Subsequently, $1 \mathrm{ml}$ of the extracted solution was filtered through $0.2 \mathrm{~mm}$ PTFE filters in HPLC umber vial. Punicalagin standard was prepared by dissolving $0.5 \mathrm{mg}$ in $1 \mathrm{ml}$ of $100 \%$ methanol. Samples were then filtered through 0.2 mm PTFE filters into HPLC amber vial for HPLC and LC-MS analysis.

\subsubsection{HPLC Analysis}

HPLC analyses were conducted using Agilent Technologies 1200 series HPLC (Santa Clara, CA, USA) with a photodiode array (PDA) detector and an auto sampler. Chemstation software was used to control the experiment and for quantification of phenolic compounds. Hydrolysable tannin separation was undertaken using a PhenomenexSynergi $4 \mu \mathrm{m}$ Hydro-RP 80A column $(250 \mathrm{~mm} \times 4.6 \mathrm{~mm} \times 5 \mu \mathrm{m}$, Torrance, CA, USA). The mobile phase was $2 \%$ acetic acid in distilled $\mathrm{H}_{2} \mathrm{O}$ (solvent $\mathrm{A}$ ) and $0.5 \%$ acetic acid in $50 \%$ acetonitrile in water (solvent B). The flow rate was $1 \mathrm{ml} / \mathrm{min}$ with a step gradient of $10 \%, 55 \%, 100 \%, 10 \%$ and $10 \%$ of solvent $\mathrm{B}$ at $0,10,13$, 15 and $20 \mathrm{~min}$, respectively. Samples, filtered through $0.2 \mathrm{~mm}$ PTFE filters, were injecting $(10 \mu \mathrm{L})$ on the HPLC column $\left(25^{\circ} \mathrm{C}\right)$. Peak areas recorded at $280 \mathrm{~nm}$ were quantified using a calibration curve obtained with punicalagin reference standard. [15].

\subsubsection{LC-MS Analysis}

Following HPLC analysis, the samples were injected on to the LC-MS Electrospray ionization ion-trap time-offlight mass spectrometry (Shimadzu Scientific Instruments, Columbia, MD, USA) system for structural elucidation. PJE and standards were analysed on Phenomenex C18 column (250 mm $\times 3.0 \mathrm{~mm} \times 5 \mu \mathrm{m}$, Torrance, CA, USA). The mobile phase consisted of $0.1 \%$ formic acid in distilled $\mathrm{H}_{2} \mathrm{O}$ (solvent $\mathrm{A}$ ) and $0.1 \%$ formic acid in methanol (solvent B). The flow rate was set at $0.4 \mathrm{~mL} / \mathrm{min}$ with a step gradient of $5 \%, 8 \%, 14 \%, 14 \%, 25 \%$, $85 \%$ and $5 \%$ of solvent B at $0,5,15,25,30,32$, and $40 \mathrm{~min}$, respectively. Samples were filtered through $0.2 \mathrm{~mm}$ PTFE filters before injecting $5 \mu \mathrm{L}$ on the LC-MS column $\left(25^{\circ} \mathrm{C}\right)$. Quantification of the compound was performed from the peak areas recorded at $250 \mathrm{~nm}$ to the calibration curve obtained with reference standards punicalagin [16].

\subsubsection{DPPH Radical Scavenging Activity}

The total radical scavenging capacity of pomegranate juice and punicalagin was determined by the Bersuder et al. (1998) method; this method was used to measure the reducing ability of antioxidants. Trolox and BHT were prepared with a concentration of $0.1 \mathrm{mg} / \mathrm{ml}$ dissolved in deionised water whereas alcoholic DPPH concentration was set to $0.02 \%(\mathrm{w} / \mathrm{v})$ in $99.5 \%$ ethanol. Different concentrations of $0.05,0.1$ and $0.15 \mathrm{mg} / \mathrm{ml}$ were prepared from pomegranate juice and punicalagin. Both control and blank samples were prepared in triplicate. A sample/control of $500 \mu \mathrm{l}$ was added to $500 \mu \mathrm{l} 99.5 \%$ ethanol, and $125 \mu \mathrm{l}$ of DPPH was then added to the solution and vortexed thoroughly. All samples were incubated in the dark for one hour; the absorption of the solution was read in the spectrometer calibrated with a phosphate buffer at $517 \mathrm{~nm}$ [17]. A blank was also prepared where 
$500 \mu \mathrm{l}$ of deionised water was used instead. The DPPH radical scavenging activity was then calculated as follows:

$$
\% \text { of DPPH inhibition }=[(\mathrm{AC}-\mathrm{AS}) / \mathrm{AC}] \times 100
$$

where: AC represents the absorbance of the control which contains DPPH, and AS refers to the absorbance pomegranate/punicalagin in the presence of DPPH.

\subsubsection{Scavenging of Hydrogen Peroxide $\left(\mathrm{H}_{2} \mathrm{O}_{2}\right)$}

The ability of pomegranate juice and punicalagin to scavenge hydrogen peroxide was determined by the Gulcin et al. (2005) method. Different concentrations from experimental samples have been studied. $\mathrm{H}_{2} \mathrm{O}_{2}(40 \mathrm{mM})$ was prepared in phosphate buffer saline at $\mathrm{pH} 7.4(\mathrm{v} / \mathrm{v})$, and $0.6 \mathrm{ml}$ was added to $1 \mathrm{ml}$ of each pomegranate and punicalagin. The solutions were then incubated for 10 minutes and read at $230 \mathrm{~nm}$ [18]. The absorbance of the positive controls of $0.0 .1 \mathrm{mg} / \mathrm{ml} \mathrm{BHT}$ and trolox were measured. The percentage inhibition activity was calculated as follows:

$$
\% \text { of } \mathrm{H}_{2} \mathrm{O}_{2} \text { inhibition }=[(\mathrm{AC}-\mathrm{AS}) / \mathrm{AC}] \times 100
$$

where AC is the absorbance of the control with $\mathrm{H}_{2} \mathrm{O}_{2}$ and AS is the absorbance of testing sample in the presence of $\mathrm{H}_{2} \mathrm{O}_{2}$.

\subsubsection{Ferrous Chelating Activity}

Ferrous ion was measured by inhibiting the formation of ferrous-ferrozine complex after adding the components under test (pomegranate juice and punicalagin) following a modified method by Dinis et al. (1994). The chelating activity of substances was measured at $562 \mathrm{~nm}$. Concentrations of $0.05,0.1$ and $0.15 \mathrm{mg}$ of pomegranate juice and punicalagin were investigated. Slight modifications were made to the published method, wherein 1.5 $\mathrm{ml}$ of deionised water and $50 \mu \mathrm{l}$ of $2 \mathrm{mM} \mathrm{FeCl}_{2}(\mathrm{w} / \mathrm{v}$ ) were added to $500 \mu \mathrm{l}$ of sample then vortexed. After 30 seconds, $100 \mu \mathrm{l}$ of $5 \mathrm{mM}$ of ferrozine $(\mathrm{w} / \mathrm{v})$ was added to the solution. The final solution was incubated for 10 minutes at room temperature, and its absorption was read at $562 \mathrm{~nm}$ [19]. Each sample of the above concentrations was prepared in triplicates with a blank for each concentration. A 0.01\% EDTA solution was used as a positive control in this experiment. The chelating activity of the pomegranate juice and punicalagin for $\mathrm{Fe}^{2+}$ were calculated as:

$$
\% \text { of Ferrous Chelating }=[(\mathrm{AC}-\mathrm{AS}) / \mathrm{AC}] \times 100
$$

where: $\mathrm{AC}$ is the absorbance of the control that contains $\mathrm{FeCl}_{2}$ and ferrozine complex and AS is the treated sample in the presence of $\mathrm{FeCl}_{2}$ and ferrozine complex.

\subsubsection{Reducing Power Assay}

The reducing power of pomegranate juice and punicalagin were quantified by the Yildirim et al. (2000) method. This method is based on determining the ability of the tested material to reduce $\mathrm{Fe}^{3+}(\mathrm{CN})_{6}$ to $\mathrm{Fe}^{2+}(\mathrm{CN})_{6}$, in which the formed Perl's Prussian Blue complex was measured at $700 \mathrm{~nm}$. A solution of $1 \mathrm{ml}$ from each sample (with concentrations of $0.05,0.1$ and $0.15 \mathrm{mg} / \mathrm{ml}$ of water) was added to $2.5 \mathrm{ml}$ of $0.2 \mathrm{M} \mathrm{pH} 6.6$-phosphate buffer $(\mathrm{w} / \mathrm{v})$ and $2.5 \mathrm{ml}$ of $1 \%$ potassium ferricyanide $(\mathrm{w} / \mathrm{v})$. This mixture was incubated at $50^{\circ} \mathrm{C}$ for 30 minutes in a water bath. The reaction mixture was subsequently acidified by adding $2.5 \mathrm{ml}$ of $10 \%$ TCA (w/v) and centrifuged at $1600 \mathrm{rpm}$ for 10 minutes at $10^{\circ} \mathrm{C}$. Finally, $2.5 \mathrm{ml}$ of supernatant was mixed with 2.5 ml deionised water and $0.5 \mathrm{ml}$ of $1 \%$ ferric chloride $(\mathrm{w} / \mathrm{v})$. The resultant mixture was then incubated for 10 minutes at room temperature, after which its absorbance was read at $700 \mathrm{~nm}$; higher absorbance of the reaction mixtures indicates a higher reducing power [20]. This experiment was repeated three times to verify the results.

\subsubsection{Statistical Analysis}

All experiments were presented as mean \pm SD. All measurements were replicated three times. The data were statistically analysed using Graph Pad Prism. Differences between pomegranate arils and punicalagin were assessed by unpaired t-test. A one-way analysis of variance followed by Bonferroni's test testing between treatments and controls was performed. Values of $\mathrm{p} \leq 0.01$ were considered significant. 


\section{Results}

\subsection{Total Phenol and Flavonoid Content}

The quantitative determination of the total phenolic content was expressed in mg of gallic acid corresponding to $40 \mathrm{mg}$ dry weight of pomegranate arils. The content of polyphenols was $118.56 \mu \mathrm{g}$ of gallic acid/40 $\mathrm{mg}$ and the total flavonoid content of the pomegranate juice was $31.5 \mu \mathrm{g}$ of catechin $/ 60 \mathrm{mg}$ of dry weight of pomegranate arils.

\subsection{HPLC and LC-MS Analysis}

Methanol extracts of pomegranate husk acquired from a local store in the United States and freeze-dried pomegranate arils from United States and United Kingdom were applied to HPLC. The LC-MS analysis was undertaken for pomegranate husk, pomegranate juice methanol extracts and compared with punicalagin standard. The HPLC and LC-MS chromatograms are illustrated in Figures 1-3, respectively. There was a high degree of similarity found between the punicalagin standard and methanol extract from pomegranate husk.

The retention time was 17 minutes for the total run of 20 minutes in HPLC and 40 minutes for a total run of 40 minutes. In contrast, the chromatograms resulting from the methanol extract for pomegranate juice from both countries did not show any peak for punicalagin.

\subsection{DPPH Radical Scavenging Activity}

The mechanism of antioxidant action differs from one component to another; consequently it cannot be assumed that only one mechanism reflects the antioxidant activity of the compounds. For this reason, investigation of different antioxidant mechanisms has been adopted in this study.

DPPH exists as a stabilised free radical, which has a deep violet colour with an absorbance wavelength of 520 $\mathrm{nm}$. In the presence of antioxidants, the DPPH radical form is converted to a DPPH-H non-radical form. The ability to bleach the purple colour to yellow indicates the efficacy of the antioxidant component. When the odd electron in DPPH accepts a hydrogen atom or electron from the antioxidant, the absorbance decreased proportionally due to the increase in the non-radical form of DPPH. The changes in the DPPH radical scavenging effects of pomegranate juice and punicalagin at different concentrations $(0.05,0.1$ and $0.15 \mathrm{mg} / \mathrm{ml})$ are shown in Figure 4.

(a)

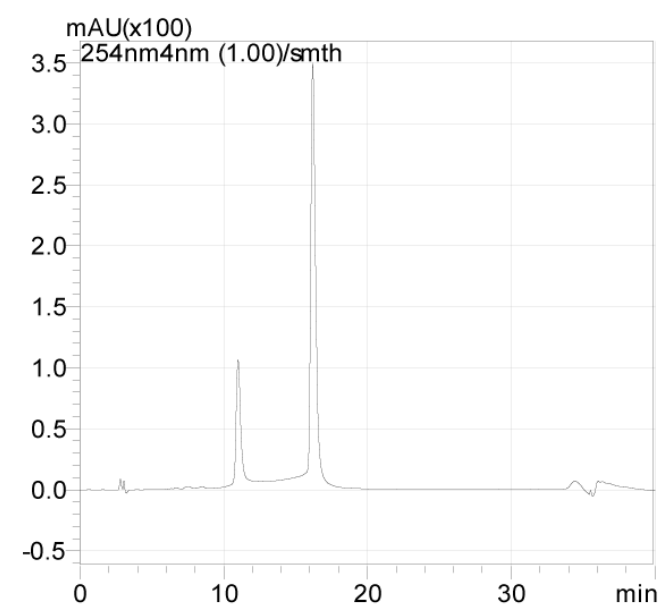

\section{(b)}

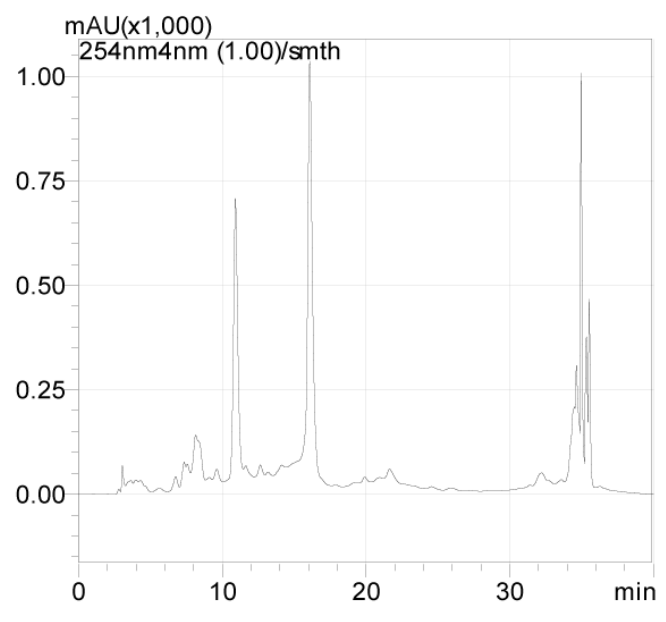

Figure 1. HPLC analysis of punicalagin and pomegranate husk. $\mathrm{a}=$ punicalagin standard, $\mathrm{b}=$ US pomegranate husk in 50\% methanol. Separation conditions were: column PhenomenexSynergi $4 \mu \mathrm{m}$ Hydro-RP $80 \mathrm{~A}$ (250 $\mathrm{mm} \times 4.6 \mathrm{~mm} \times 5 \mu \mathrm{m}$, Torrance, CA, USA). Column temperature: $25^{\circ} \mathrm{C}$. Mobile phase: Solvent a $=2 \%$ acetic acid in distilled $\mathrm{H}_{2} \mathrm{O}$, Solvent $\mathrm{b}=0.5 \%$ acetic acid in 50\% acetonitrile in water. Gradient condition: $10 \%, 55 \%$ $100 \%, 10 \%$ and $10 \%$ at $0,10,13,15$ and $20 \mathrm{~min}$, respectively. The flow rate: $1 \mathrm{ml} / \mathrm{min}$, recorded at $280 \mathrm{~nm}$. a $=$ punicalagin standard and, $\mathrm{b}=$ methanol extract for pomegranate husk. 
(a)

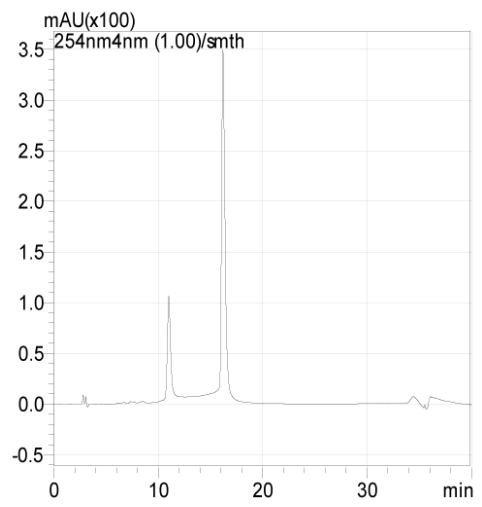

(b)

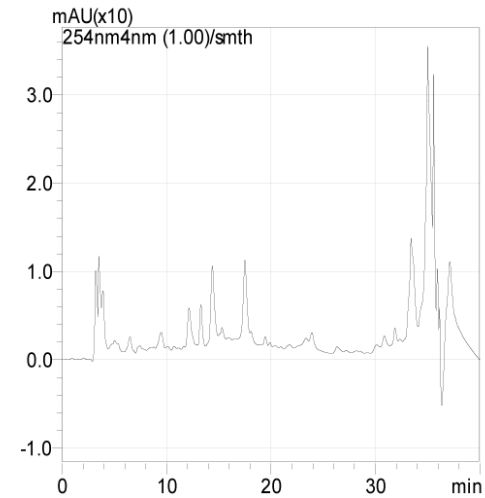

(c)

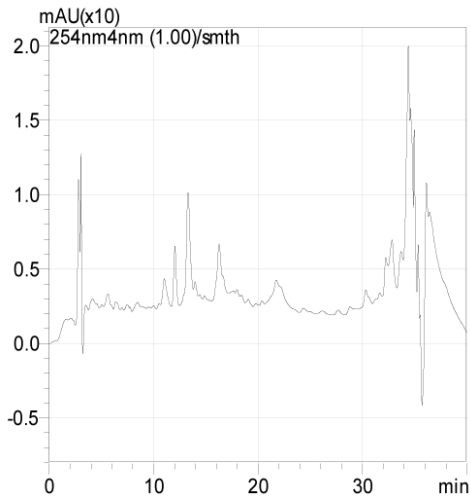

Figure 2. HPLC analysis of punicalagin and pomegranate juice. $\mathrm{a}=$ punicalagin standard, $\mathrm{b}=\mathrm{US}$ handy pomegranate juice and c = UK handy pomegranate juice extracted in 50\% methanol. Separation conditions were: column PhenomenexSynergi 4 $\mu \mathrm{m}$ Hydro-RP 80A (250 mm $\times 4.6 \mathrm{~mm} \times 5 \mu \mathrm{m}$, Torrance, CA, USA). Column temperature: $25^{\circ} \mathrm{C}$. Mobile phase: Solvent a = $2 \%$ acetic acid in distilled $\mathrm{H}_{2} \mathrm{O}$, Solvent $\mathrm{b}=0.5 \%$ acetic acid in $50 \%$ acetonitrile in water. Gradient condition: $10,55,100$, 10 and $10 \%$ at $0,10,13,15$ and $20 \mathrm{~min}$, respectively. The flow rate: $1 \mathrm{ml} / \mathrm{min}$, recorded at $280 \mathrm{~nm}$.

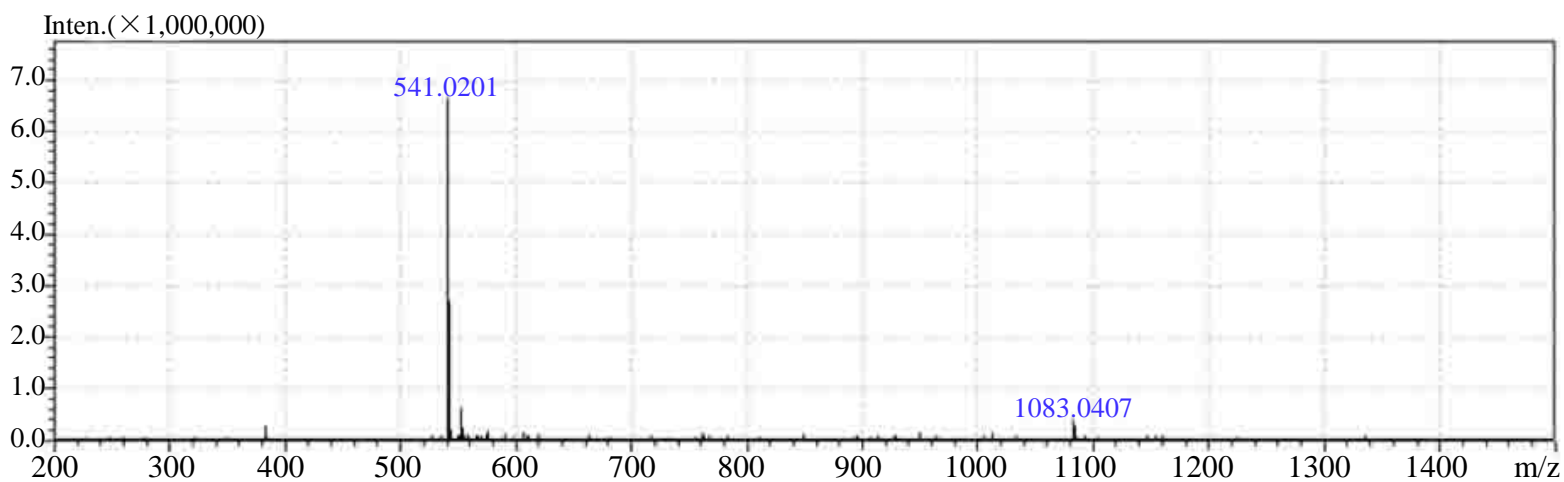

(a)

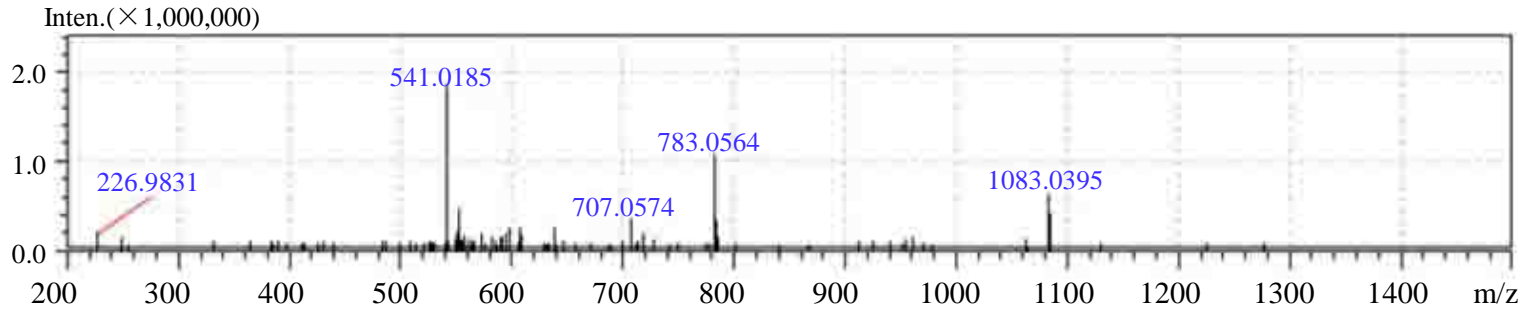

(b)

Figure 3. Identification of punicalagin in methanol extract of pomegranate husk by LC-MS. Identification conditions were: column C18 $\left(250 \mathrm{~mm} \times 3.0 \mathrm{~mm} \times 5 \mu \mathrm{m}\right.$, Torrance, CA, USA). Column temperature: $25^{\circ} \mathrm{C}$. Mobile phase: Solvent a $=0.1 \%$ formic acid in distilled $\mathrm{H}_{2} \mathrm{O}$, Solvent $\mathrm{b}=0.1 \%$ formic acid in methanol. Gradient conditions: $5 \%$ - 85\% solvent B followed by $10 \mathrm{~min}$ re-equilibration. Flow rate: $0.4 \mathrm{ml} / \mathrm{min}$ monitord at $250 \mathrm{~nm}$. a = punicalagin standard, $\mathrm{b}=$ methanol extract of pomegranate husk.

The percentages of inhibition caused by pomegranate juice were $14.4 \%, 27.5 \%$ and $37.9 \%$ for the concentrations $(0.05,0.1$ and $0.15 \mathrm{mg} / \mathrm{ml})$, respectively, while the scavenging activity in the presence of punicalagin at the same concentrations was (12.5\%, 23.9\% and 30.8\%), respectively. The DPPH radical scavenging effects increased in proportion to the dose. It was noted that at 0.1 and $0.15 \mathrm{mg} / \mathrm{ml}$ pomegranate juice, radical scavenging was significant as compared with punicalagin at the same concentrations $(\mathrm{p} \leq 0.01)$.

This radical scavenging activity of pomegranate juice and punicalagin at $0.1 \mathrm{mg} / \mathrm{ml}$ was compared to 0.1 $\mathrm{mg} / \mathrm{ml}$ of trolox and BHT individually. DPPH radical scavenging activity was significantly increased by trolox 


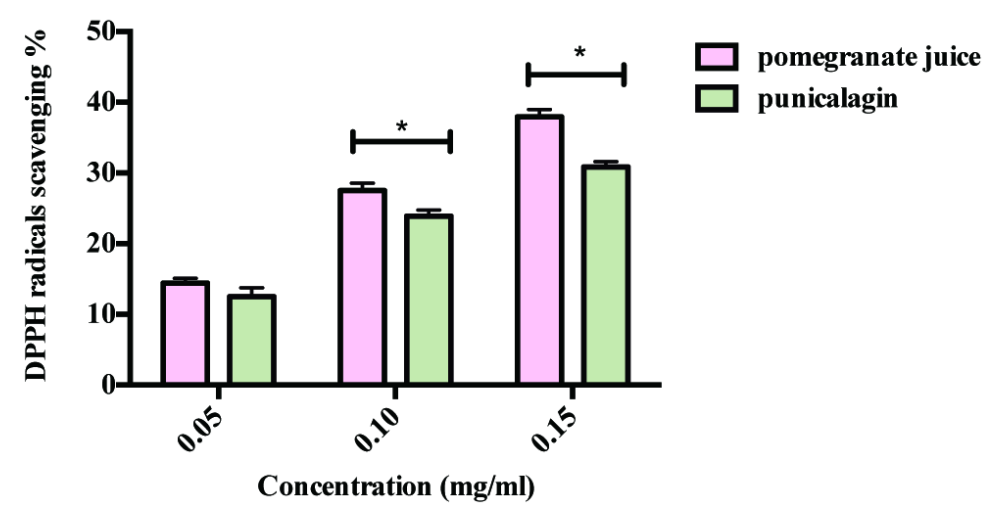

Figure 4. DPPH radical scavenging activity by pomegranate juice and punicalagin. Concentrations of both components were $0.05,0.1$ and $0.15 \mathrm{mg} / \mathrm{ml}$. Each value is expressed as mean $\pm \mathrm{SD}(\mathrm{n}=3)$ of triplicate measurements. Comparisons of means were made using unpaired t-test $(*=\mathrm{p}<0.05$, ns $=$ non significant).

compared to $0.1 \mathrm{mg} / \mathrm{ml}$ of pomegranate juice and punicalagin $(\mathrm{p} \leq 0.0001)$ the percent of inhibition was $66,27.5$ and 23.9\% respectively. However, there was no significant difference in DPPH radical scavenging activity between BHT, pomegranate juice and punicalagin ( $\mathrm{p}>0.01$ ), the percent inhibition was 24\%, 27.5\% and 23.9\% respectively (Figure 5(a) and Figure 5(b)).

\subsection{Scavenging of Hydrogen Peroxide $\left(\mathrm{H}_{2} \mathrm{O}_{2}\right)$}

The ability of pomegranate juice and punicalagin to scavenge $\mathrm{H}_{2} \mathrm{O}_{2}$ was measured at 320 nm. The presence of phenolic groups in pomegranate juice and punicalagin give them the ability to donate an electron to $\mathrm{H}_{2} \mathrm{O}_{2}$ and convert it to $\mathrm{H}_{2} \mathrm{O}$ [21]. There was significant inhibition percent of pomegranate juice compared with punicalagin at the highest concentration $(\mathrm{p}<0.001)$ as depicted in Figure 6.

The percent of inhibition activity of $\mathrm{H}_{2} \mathrm{O}_{2}$ was $14 \%, 17 \%$ and $30 \%$ for $0.05,0.1$ and $0.15 \mathrm{mg} / \mathrm{ml}$ of pomegranate juice respectively. On the other hand, the percent of $\mathrm{H}_{2} \mathrm{O}_{2}$ scavenging by $0.05,0.1$ and $0.15 \mathrm{mg} / \mathrm{ml}$ of punicalagin was $11 \%, 17 \%$ and $18 \%$ respectively. Both compounds showed scavenging of $\mathrm{H}_{2} \mathrm{O}_{2}$ with increasing concentrations.

Figure 7(a) and Figure 7(b) illustrates the activity of $0.1 \mathrm{mg} / \mathrm{ml}$ trolox and BHT compared with $0.1 \mathrm{mg} / \mathrm{ml}$ pomegranate juice and punicalagin. Scavenging activity values for trolox, BHT, pomegranate juice and punicalagin were $19 \%, 13 \%, 17 \%$ and $17.8 \%$ respectively. The pomegranate juice and punicalagin showed a significant increase in the scavenging of $\mathrm{H}_{2} \mathrm{O}_{2}$ compared with BHT (p < 0.001). However, no significant difference was observed between trolox, pomegranate juice and punicalagin. Although $\mathrm{H}_{2} \mathrm{O}_{2}$ itself is a weak oxidant, it is sometimes toxic to the cell because it may give rise to a hydroxyl radical in the cell [22], which results in lipid peroxidation as described in the introduction chapter (1.3.2).

\subsection{Ferrous Chelating Activity}

With regards to ferrous ion chelating ability, the formation of $\mathrm{Fe}^{2+}$-ferrozine complex is inhibited in the presence of antioxidant. The antioxidant that has the ability to inhibit the formation of this complex is expressed as Fe ${ }^{2+}$ chelatinon. The chelation of ferrous ions by pomegranate juice and punicalagin is shown in Figure 8 . Both components chelater ferrous ion in a dose dependent-manner; at $0.15 \mathrm{mg} / \mathrm{ml}$ punicalagin was significantly higher than pomegranate juice as ferrous chelator $(\mathrm{p} \leq 0.01)$. A standard metal chelating agent used in this experiment was EDTA. Ferrous chelating activity of EDTA was 97\% while, for pomegranate juice and punicalagin, chelating activity were lower at $14 \%$ and $18 \%$ respectively (Figure 9 ).

\subsection{Reducing Power Assay}

Reducing power reflects the electron donating capacity of bioactive compounds; a mechanism also known as antioxidant activity. It measures the reduction of $\mathrm{Fe}^{3+} / \mathrm{Fe}^{2+}$ thiocyanide in the presence of antioxidants; the 


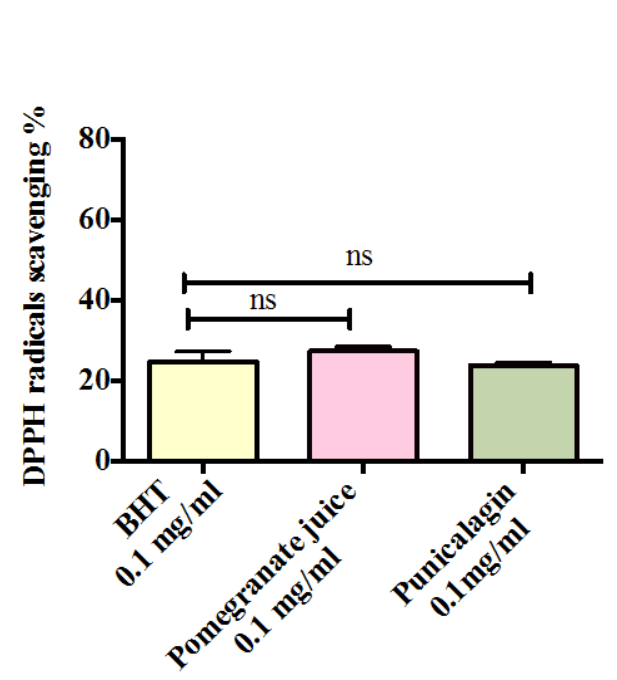

(a)

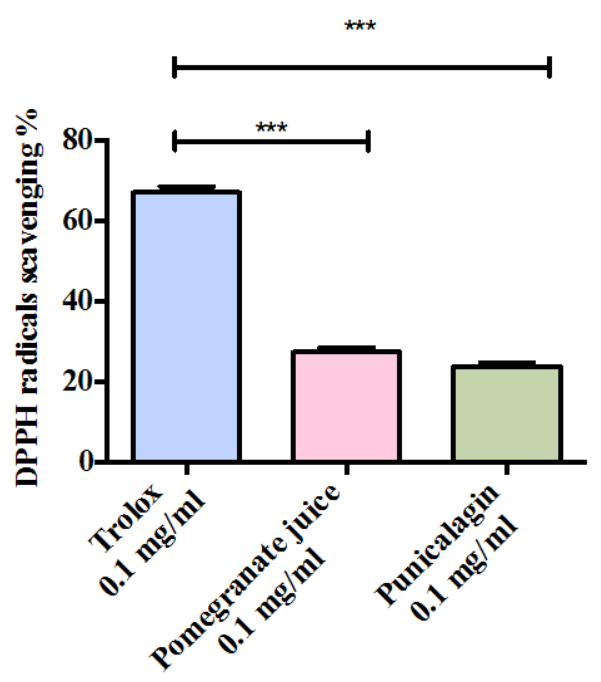

(b)

Figure 5. Comparison between DPPH radical scavenging activity of punicalagin, pomegranate juice, trolox and BHT. Concentration was $0.1 \mathrm{mg} / \mathrm{ml}$ for all components. Values are mean \pm SD of three determinations. Comparisons of means were made using a one-way ANOVA followed by Bonferroni's test $(* * *=\mathrm{p}<0.0001, \mathrm{~ns}=$ non significant $)$.

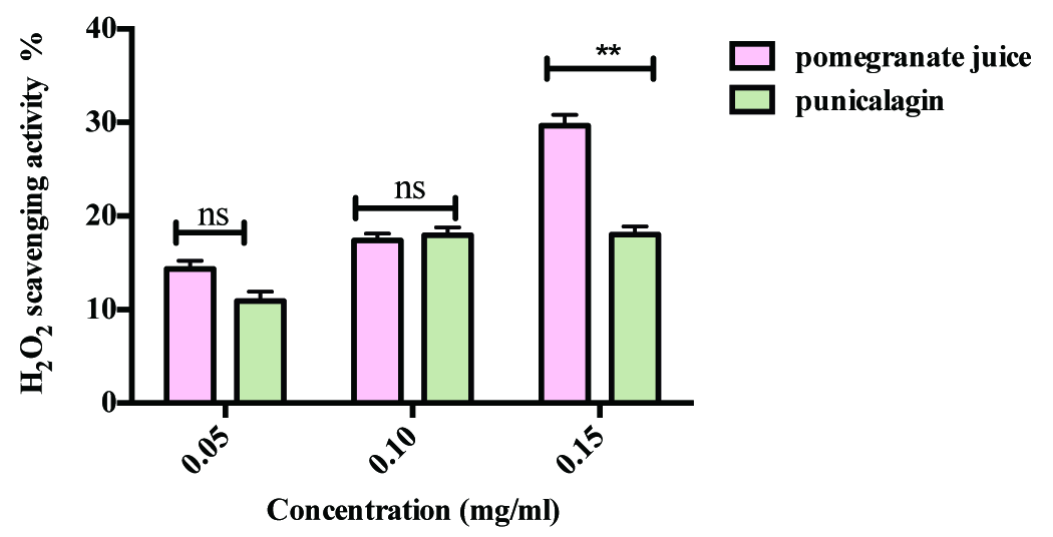

Figure 6. $\mathrm{H}_{2} \mathrm{O}_{2}$ scavenging activity of pomegranate juice and punicalagin. Concentrations were $0.05,0.1$ and $0.15 \mathrm{mg} / \mathrm{ml}$. Each value is expressed as mean \pm SD of triplicate measurements. Comparisons of means were made using unpaired t-test $(* *=\mathrm{p}<0.001$, ns $=$ non significant $)$.

resulting ferrocyanids form a complex with ferric chloride. The results showed an increase in the absorbance at $700 \mathrm{~nm}$ and, therefore, an increase in the reductive ability of pomegranate juice and punicalagin [18]. Figure 10 illustrates the reducing activities corresponding to the concentration range $(0.05,0.1$ and $0.15 \mathrm{mg} / \mathrm{ml})$ of pomegranate juice and punicalagin. The reducing activity for both treatments increased in a dose dependent manner. The reducing activity shown by punicalagin increased significantly compared with pomegranate juice ( $\mathrm{p} \leq 0.01)$ at all concentrations.

\section{Discussion}

Punicalagin was found in pomegranate husk but not in pomegranate juice when analysed by HPLC and LC-MS. Most research on pomegranate has established that phenolic compounds such as punicalagin, gallic acid, and ellagic acid are in high quantities in pomegranate husk, whereas the concentration of anthocyanins like delphinidin, cyanidin and pelargonidin is high in pomegranate juice [4] [23] [24]. These high concentrations of gallic acid, punicalagin and ellagic acid were found in both pomegranate husk and commercial juice because the majority of phenolic compounds were extracted during the pressing process [4] [23]. 


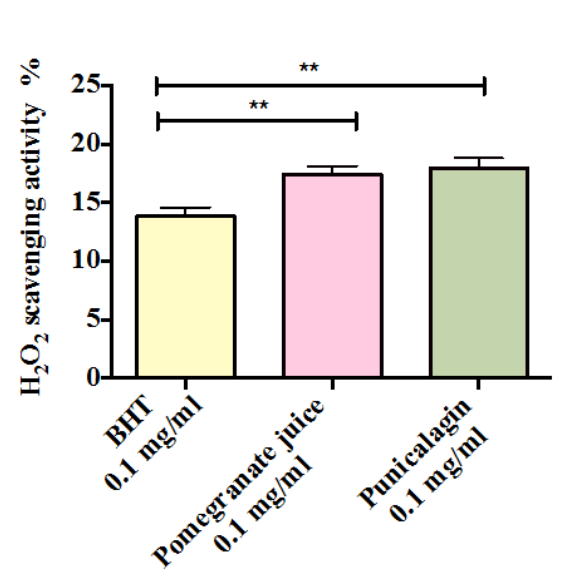

(a)

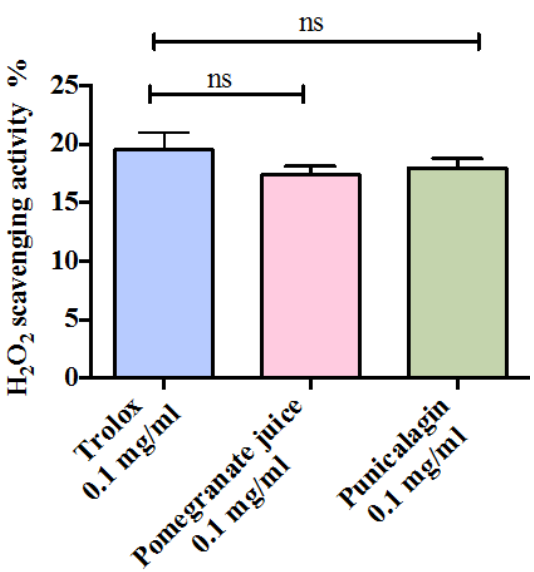

(b)

Figure 7. Comparison of $\mathrm{H}_{2} \mathrm{O}_{2}$ scavenging activity of pomegranate juice, punicalagin, trolox and BHT. Concentration was $0.1 \mathrm{mg} / \mathrm{ml}$. Values are mean \pm SD of three experiments. Comparisons of means were made using a one-way ANOVA followed by Bonferroni's test $(* *=p<0.001$, ns $=$ non significant $)$.

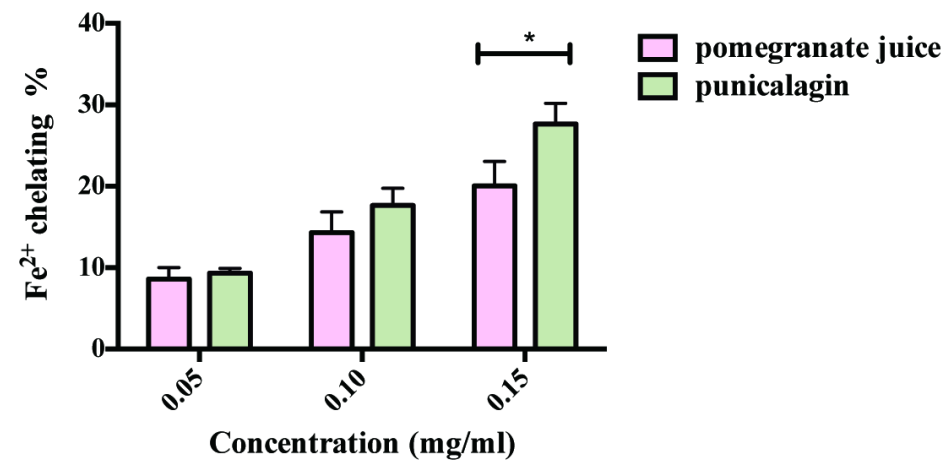

Figure 8. Ferrousion chelating activity by pomegranate juice and punicalagin. Concentrations were $0.05,0.1$ and $0.15 \mathrm{mg} / \mathrm{ml}$. Each value is the mean $\pm \mathrm{SD}$ of three measurements. Comparisons of means were made using unpird t-test $(*=p<0.01)$.

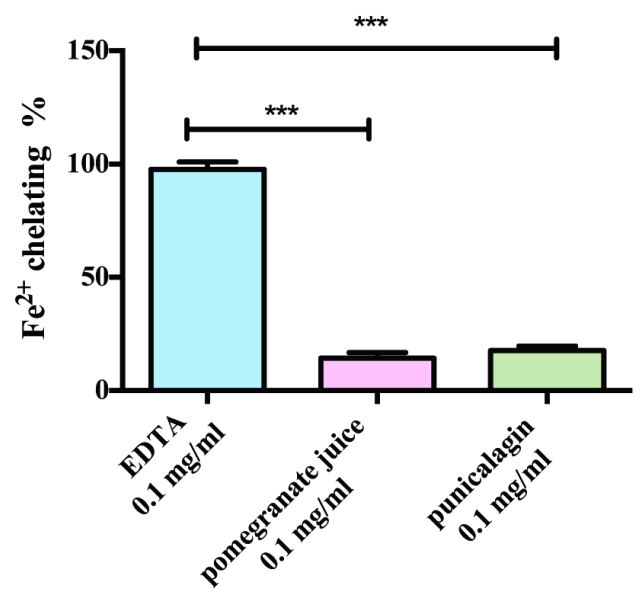

Figure 9. Metal chelating activity of pomegranate juice, punicalagin and EDTA. Concentration was $0.1 \mathrm{mg} / \mathrm{ml}$. Values are mean \pm SD of three experiments. Comparisons of means were made using a one-way ANOVA followed by Bonferroni's test ( ${ }^{* * *}=\mathrm{p}<$ 0.0001). 


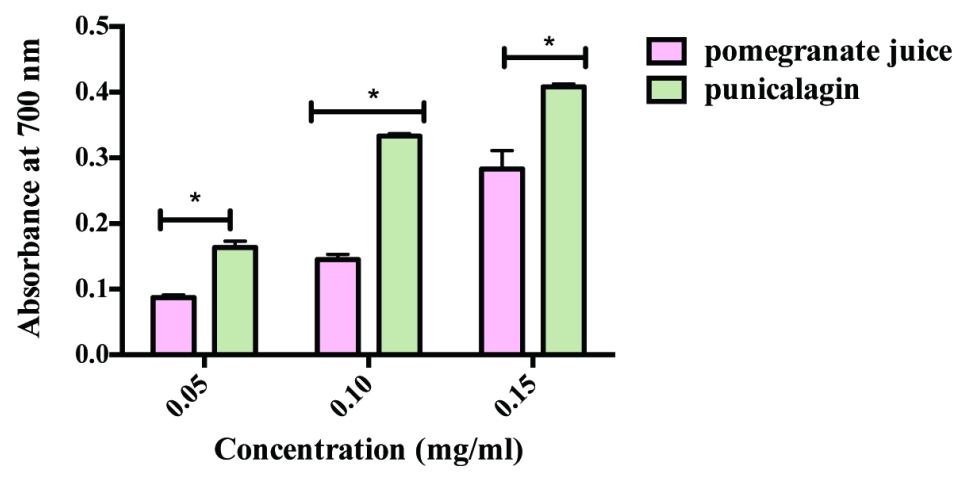

Figure 10. Reducing power of different concentrations from pomegranate juice and punicalagin. Each value is expressed as mean \pm SD. Each value is the means $\pm \mathrm{SD}$ of three measurements. Comparisons of means were made using unpird t-test $(*=\mathrm{p}<0.01)$.

In the present work, the antioxidant mechanism of punicalagin and pomegranate water extract was investigated. The DPPH radical scavenging activity assay has previously been used to measure the free radical scavenging effectiveness of different polyphenols [17] [25]. In the present study, inhibition of $\mathrm{DPPH}^{\bullet}$ by pomegranate juice or punicalagin was increased with increasing concentration $(0.05-0.15 \mathrm{mg} / \mathrm{ml})$. Pomegranate juice showed significant inhibition of $\mathrm{DPPH}^{*}$ compared with punicalagin at concentrations between 0.1 and 0.15 $\mathrm{mg} / \mathrm{ml}(\mathrm{p}<0.05)$. Thus, pomegranate juice exhibits greater ability to donate hydrogen atoms to reduce the stable radical $\mathrm{DPPH}^{\bullet}$ to its non-radical form (DPPH-H) than punicalagin. The inhibition of DPPH radical activity caused by natural (trolox) and synthetic (BHT) antioxidants (positive controls) at $0.1 \mathrm{mg} / \mathrm{ml}$ was compared with pomegranate and punicalagin at the same concentration. Compared with BHT, pomegranate juice and punicalagin inhibited the $\mathrm{DPPH}^{\bullet}$ radical activity to a similar extent. In contrast, an equivalent concentration of trolox 0.1 $\mathrm{mg} / \mathrm{ml}$ significantly inhibited $\mathrm{DPPH}^{\bullet}$ greater degree than punicalagin or pomegranate juice $(\mathrm{p}<0.0001$ for both examples components). Several polyphenols such as tannins and anthocyanins have demonstrated antioxidant properties through scavenging the $\mathrm{DPPH}^{\bullet}$ radical [26].

The second radical scavenging mechanism for punicalagin and pomegranate juice as $\mathrm{H}_{2} \mathrm{O}_{2}$ scavenger was examined. $\mathrm{H}_{2} \mathrm{O}_{2}$ has an effect on lipid peroxidation; however, it can sometimes cause cytotoxicity if it generates hydroxyl radicals [27]. The hydroxyl radical is a very reactive free radical, which can initiate lipid peroxidation [10]. In this study, both punicalagin and pomegranate juice showed scavenging activity towards $\mathrm{H}_{2} \mathrm{O}_{2}$, which was dose dependent. Pomegranate juice demonstrated significant scavenging of $\mathrm{H}_{2} \mathrm{O}_{2}$ compared with punicalagin at $0.15 \mathrm{mg} / \mathrm{ml}(\mathrm{p}<0.001)$; the percent inhibition was $30 \%$ and $18 \%$ for pomegranate juice and punicalagin, respectively. In addition, pomegranate juice and punicalagin showed significant inhibition of $\mathrm{H}_{2} \mathrm{O}_{2}$ at $0.1 \mathrm{mg} / \mathrm{ml}$ compared with BHT at the same concentration ( $<0.001$ for both experimental components). However, no significant difference was observed when punicalagin and juice were compared with trolox. The percent of inhibition was $19 \%, 17 \%$, and $17 \%$ for trolox, pomegranate juice, and punicalagin, respectively.

The ability of punicalagin and pomegranate juice to act as ferrous chelating agents was examined in order to study their antioxidant effects further. Ferrous metal $\left(\mathrm{Fe}^{2+}\right)$ ions are reactive and can induce free radical formation via the Fenton reaction:

$$
\mathrm{Fe}^{2+}+\mathrm{H}_{2} \mathrm{O}_{2} \rightarrow \mathrm{Fe}^{3+}+\mathrm{OH}+\cdot \mathrm{OH}[10]
$$

Consequently, this radical can initiate lipid peroxidation [28]. The amount of $\mathrm{Fe}^{2+}$-ferrozin complex was significantly reduced in a dose-dependent manner in the presence of punicalagin and pomegranate juice at concentrations of $0.05-0.15 \mathrm{mg} / \mathrm{ml}$. At $0.15 \mathrm{mg} / \mathrm{ml}$ concentration ferrous chelating activity of punicalagin was significantly higher than for pomegranate juice $(\mathrm{p} \leq 0.05)$. The positive control (EDTA) showed $97 \%$ complex inhibition, while punicalagin and pomegranate juice showed $18 \%$ and $14 \%$ inhibition at $0.1 \mathrm{mg} / \mathrm{ml}$, respectively. It has been established that, due to the presence of several hydroxyl groups, many phenolic compounds can bind with metal ions such as $\mathrm{Fe}^{2+}$ or $\mathrm{Cu}^{2+}$ and prevent free radical formation [29]. Moreover, moderate free-radical scavenging components often have strong metal chelation capacity [30].

The potential of pomegranate juice and punicalagin to act as reducing agents was also tested. Punicalagin and pomegranate juice appeared to have reducing activity associated with increased concentrations $(0.05-0.15$ 
$\mathrm{mg} / \mathrm{ml})$. Reduction of ferric $\left(\mathrm{Fe}^{3+}\right)$ to ferrous $\left(\mathrm{Fe}^{2+}\right)$ iron by pomegranate juice and punicalagin has been demonstrated in this study. Both compounds have the ability to reduce $\mathrm{Fe}^{3+}$ to $\mathrm{Fe}^{2+}$ in a dose-dependent manner. Punicalagin was a more powerful reducing agent than pomegranate juice at all concentrations $(0.05-0.15 \mathrm{mg} / \mathrm{ml}$; $\mathrm{p}$ $\leq 0.05)$. As reported by Gill et al. (2000) punicalagin contains 16 phenolic hydroxyls per molecule, while the manual extract of pomegranate juice contains higher concentrations of anthocyanins than the tannin compounds. This may help to explain the high reducing activity of punicalagin compared with the pomegranate juice extract.

\section{Conclusion}

The study confirmed that punicalagin was present in high concentrations in pomegranate husk compared to pomegranate juice, as measured using a punicalagin standard. All experiments on pomegranate juice and punicalagin to determine the antioxidant mechanism concluded that pomegranate juice has a significantly higher radical scavenging activity in comparison with punicalagin $(\mathrm{p} \leq 0.01)$. However, punicalagin showed significant ferrous chelating activity ability as compared with pomegranate juice. Both of these tested samples had the ability to reduce $\mathrm{Fe}^{3+}$ ion to $\mathrm{Fe}^{2+}$. However, punicalagin showed significant reducing power ability in a dose-dependent manner compared with pomegranate juice. Nonetheless, both the pomegranate juice and punicalagin depict the ability to scavenge $\mathrm{H}_{2} \mathrm{O}_{2}$. In addition, both punicalagin and pomegranate juice showed non-significant inhibition of DPPH radicals compared with BHT and significant scavenging of $\mathrm{H}_{2} \mathrm{O}_{2}$ compared with BHT. Although, the DPPH radicals were significantly inhibited by trolox compared with punicalagin and pomegranate juice, there was no significant difference found in $\mathrm{H}_{2} \mathrm{O}_{2}$ scavenging for both pomegranate juice and punicalagin compared with trolox.

\section{References}

[1] Finley, J.W., Kong, A.N., Hintze, K.J., Jeffery, E.H., Ji, L.L. and Lei, X.G. (2011) Antioxidants in Foods: State of the Science Important to the Food Industry. Journal of Agricultural and Food Chemistry, 59, 6837-6846. http://dx.doi.org/10.1021/jf2013875

[2] Gulcin, I. (2012) Antioxidant Activity of Food Constituents: An Overview. Archives of Toxicology, 86, 345-391. http://dx.doi.org/10.1007/s00204-011-0774-2

[3] Passamonti, S., Vrhovsek, U., Vanzo, A. and Mattivi, F. (2003) The Stomach as a Site for Anthocyanins Absorption from Food. FEBS Letters, 544, 210-213. http://dx.doi.org/10.1016/S0014-5793(03)00504-0

[4] Gil, M.I., Tomas-Barberan, F.A., Hess-Pierce, B., Holcroft, D.M. and Kader, A.A. (2000) Antioxidant Activity of Pomegranate Juice and Its Relationship with Phenolic Composition and Processing. Journal of Agricultural and Food Chemistry, 48, 4581-4589. http://dx.doi.org/10.1021/jf000404a

[5] Chen, P.S. and Li, J.H. (2006) Chemopreventive Effect of Punicalagin, a Novel Tannin Component Isolated from Terminaliacatappa, on H-ras-Transformed NIH3T3 Cells. Toxicology Letters, 163, 44-53. http://dx.doi.org/10.1016/j.toxlet.2005.09.026

[6] Kulkarni, A.P., Mahal, H.S., Kapoor, S. and Aradhya, S.M. (2007) In Vitro Studies on the Binding, Antioxidant, and Cytotoxic Actions of Punicalagin. Journal of Agricultural and Food Chemistry, 55, 1491-1500. http://dx.doi.org/10.1021/jf0626720

[7] Lee, S.I., Kim, B.S., Kim, K.S., Lee, S., Shin, K.S. and Lim, J.S. (2008) Immune-Suppressive Activity of Punicalagin via Inhibition of NFAT Activation. Biochemical and Biophysical Research Communications, 371, 799-803. http://dx.doi.org/10.1016/j.bbrc.2008.04.150

[8] Chen, P.S., Li, J.H., Liu, T.Y. and Lin, T.C. (2000) Folk Medicine Terminaliacatappa and Its Major Tannin Component, Punicalagin, Are Effective against Bleomycin-Induced Genotoxicity in Chinese Hamster Ovary Cells. Cancer Letters, 152, 115-122. http://dx.doi.org/10.1016/S0304-3835(99)00395-X

[9] Seeram, N.P., Adams, L.S., Henning, S.M., Niu, Y., Zhang, Y., Nair, M.G. and Heber, D. (2005) In Vitro Antiproliferative, Apoptotic and Antioxidant Activities of Punicalagin, Ellagic Acid and a Total Pomegranate Tannin Extract Are Enhanced in Combination with Other Polyphenols as Found in Pomegranate Juice. Journal of Nutritional Biochemistry, 16, 360-367. http://dx.doi.org/10.1016/j.jnutbio.2005.01.006

[10] Halliwell, B. (1991) Reactive Oxygen Species in Living Systems: Source, Biochemistry, and Role in Human Disease. American Journal of Medicine, 91, 14S-22S. http://dx.doi.org/10.1016/0002-9343(91)90279-7

[11] Wolfe, K.L., Kang, X., He, X., Dong, M., Zhang, Q. and Liu, R.H. (2008) Cellular Antioxidant Activity of Common Fruits. Journal of Agricultural and Food Chemistry, 56, 8418-8426. http://dx.doi.org/10.1021/jf801381y

[12] Malik, A., Afaq, F., Sarfaraz, S., Adhami, V.M., Syed, D.N. and Mukhtar, H. (2005) Pomegranate Fruit Juice for 
Chemoprevention and Chemotherapy of Prostate Cancer. Proceedings of the National Academy of Sciences USA, 102, 14813-14818. http://dx.doi.org/10.1073/pnas.0505870102

[13] Kim, N.D., Mehta, R., Yu, W., Neeman, I., Livney, T., Amichay, A., Poirier, D., Nicholls, P., Kirby, A., Jiang, W., Mansel, R., Ramachandran, C., Rabi, T., Kaplan, B. and Lansky, E. (2002) Chemopreventive and Adjuvant Therapeutic Potential of Pomegranate (Punicagranatum) for Human Breast Cancer. Breast Cancer Research and Treatment, 71, 203-217. http://dx.doi.org/10.1023/A:1014405730585

[14] Jia, Z.S., Tang, M.C. and Wu, J.M. (1999) The Determination of Flavonoid Contents in Mulberry and Their Scavenging Effects on Superoxide Radicals. Food Chemistry, 64, 555-559. http://dx.doi.org/10.1016/S0308-8146(98)00102-2

[15] Gonzalez-Barrio, R., Borges, G., Mullen, W. and Crozier, A. (2010) Bioavailability of Anthocyanins and Ellagitannins Following Consumption of Raspberries by Healthy Humans and Subjects with an Ileostomy. Journal of Agricultural and Food Chemistry, 58, 3933-3939. http://dx.doi.org/10.1021/jf100315d

[16] Lu, J., Ding, K. and Yuan, Q. (2010) One-Step Purification of Punicalagin by Preparative HPLC and Stability Study on Punicalagin. Separation Science and Technology, 46, 147-154. http://dx.doi.org/10.1080/01496391003745710

[17] Bersuder, P., Hole, M. and Smith, G. (1998) Antioxidants from a Heated Histidine-Glucose Model System. I: Investigation of the Antioxidant Role of Histidine and Isolation of Antioxidants by High-Performance Liquid Chromatography. Journal of the American Oil Chemists' Society, 75, 181-187. http://dx.doi.org/10.1007/s11746-998-0030-y

[18] Gulcin, I., Alici, H.A. and Cesur, M. (2005) Determination of in Vitro Antioxidant and Radical Scavenging Activities of Propofol. Chemical \& Pharmaceutical Bulletin (Tokyo), 53, 281-285. http://dx.doi.org/10.1248/cpb.53.281

[19] Dinis, T.C., Maderia, V.M. and Almeida, L.M. (1994) Action of Phenolic Derivatives (Acetaminophen, Salicylate, and 5-Aminosalicylate) as Inhibitors of Membrane Lipid Peroxidation and as Peroxyl Radical Scavengers. Arch Biochem Biophys, 315, 161-169. http://dx.doi.org/10.1006/abbi.1994.1485

[20] Yildirim, A., Mavi, A., Oktay, M., Kara, A.A., Algur, O.F. and Bilaloglu, V. (2000) Comparison of Antioxidant and Antimicrobial Activities of Tilia (Tilia argentea Desf EX DC), sage (Salvia triloba L.), and Black Tea (Camellia sinensis) Extracts. Journal of Agricultural and Food Chemistry, 48, 5030-5034. http://dx.doi.org/10.1021/jf000590k

[21] Ebrahimzadeh, M.A., Nabavi, S.M., Nabavi, S.F., Bahramian, F. and Bekhradnia, A.R. (2010) Antioxidant and Free Radical Scavenging Activity of H. Officinalis L. var. Angustifolius, V. Odorata, B. Hyrcana and C. Speciosum. Pakistan Journal of Pharmaceutical Sciences, 23, 29-34.

[22] Ebrahimzadeh, M.A., Nabavi, S.M. and Nabavi, S.F. (2009) Correlation between the in Vitro Iron Chelating Activity and Poly Phenol and Flavonoid Contents of Some Medicinal Plants. Pakistan Journal of Biological Sciences, 12, 934-938. http://dx.doi.org/10.3923/pjbs.2009.934.938

[23] Fischer, U.A., Carle, R. and Kammerer, D.R. (2011) Identification and Quantification of Phenolic Compounds from Pomegranate (Punica granatum L.) Peel, Mesocarp, Aril and Differently Produced Juices by HPLC-DAD-ESI/MS ${ }^{n}$. Food Chemistry, 127, 807-821. http://dx.doi.org/10.1016/j.foodchem.2010.12.156

[24] Qu, W., Breksa, A.P., Pan, Z. and Ma, H. (2012) Quantitative Determination of Major Polyphenol Constituents in Pomegranate Products. Food Chemistry, 132, 1585-1591. http://dx.doi.org/10.1016/j.foodchem.2011.11.106

[25] Gülçin, İ., Huyut, Z., Elmastaş, M. and Aboul-Enein, H.Y. (2010) Radical Scavenging and Antioxidant Activity of Tannic Acid. Arabian Journal of Chemistry, 3, 43-53. http://dx.doi.org/10.1016/j.arabjc.2009.12.008

[26] Ozcelik, B., Lee, J.H. and Min, D.B. (2003) Effects of Light, Oxygen, and pH on the Absorbance of 2,2-Diphenyl1-picrylhydrazyl. Journal of Food Science, 68, 487-490. http://dx.doi.org/10.1111/j.1365-2621.2003.tb05699.x

[27] Namiki, M. (1990) Antioxidants/Antimutagens in Food. Critical Reviews in Food Science and Nutrition, 29, $273-300$. http://dx.doi.org/10.1080/10408399009527528

[28] Yu, B.P., Laganiere, S. and Kim, J.W. (1988) Influence of Life-Prolonging Food Restriction on Membrane Lipoperoxidation and Antioxidant Status. Basic Life Sciences, 49, 1067-1073.

[29] Yoshino, M. and Murakami, K. (1998) Interaction of Iron with Polyphenolic Compounds: Application to Antioxidant Characterization. Analytical Biochemistry, 257, 40-44. http://dx.doi.org/10.1006/abio.1997.2522

[30] Wu, C., Chen, F., Wang, X., Kim, H.-J., He, G.-Q., Haley-Zitlin, V. and Huang, G. (2006) Antioxidant Constituents in Feverfew (Tanacetum parthenium) Extract and Their Chromatographic Quantification. Food Chemistry, 96, $220-227$. http://dx.doi.org/10.1016/j.foodchem.2005.02.024 